\title{
Takotsubo cardiomyopathy: serious early complications and two-year mortality - a 101 case study
}

\author{
M. Zalewska-Adamiec ${ }^{1}$ H. Bachorzewska-Gajewska ${ }^{1}$ A. Tomaszuk-Kazberuk ${ }^{2} \cdot K_{\text {. Nowak }}{ }^{1}$ \\ P. Drozdowski ${ }^{3}$ J. Bychowski ${ }^{4}$ R. Krynicki ${ }^{5}$ W. J. Musial ${ }^{2}$ S. Dobrzycki ${ }^{1}$
}

Published online: 11 July 2016

(c) The Author(s) 2016. This article is available at SpringerLink with Open Access

\begin{abstract}
Background Takotsubo cardiomyopathy (TTC) is characterised by transient contractility disturbances of the apex of the left ventricle.

Methods We enrolled 101 patients from the northern-eastern part of Poland in the years 2008-2012 who were hospitalised for TCC. The control group consisted of female patients diagnosed with anterior myocardial infarction with ST-segment elevation (anterior STEMI) $(n=101)$.

Results $89 \%$ of the study group were women. Patients with TTC had diabetes $(12.6 \%$ vs $29.7 \% ; p=0.002)$ and hyperlipidaemia $(36.8 \%$ vs $64.4 \% ; p=0.0001)$ significantly less frequently, and better kidney function assessed by estimated glomerular filtration rate versus patients with anterior STEMI $(74.52 \%$ vs $64.30 \% ; p=0.004)$. In the TTC group there were more patients with chronic obstructive pulmonary disease $(11.6 \%$ vs $1.0 \% ; p=0.002)$ and thyroid disturbances, especially hyperthyroidism $(23.4 \%$ vs $11.0 \% ; p=0.021)$. In patients with TTC sudden cardiac arrest, pulmonary oedema and cardiogenic shock were observed less frequently than in the control group (14.7\%
\end{abstract}

M. Zalewska-Adamiec

mzalewska5@wp.pl

1 Department of Invasive Cardiology, Medical University of Bialystok, Białystok, Poland

2 Department of Cardiology, Medical University of Bialystok, Białystok, Poland

3 Department of Cardiology, ProCardia in Augustow, Augustów, Poland

4 Department of Cardiology, Provincial Hospital in Bialystok, Białystok, Poland

5 Department of Cardiology, Provincial Hospital in Lomza, Łomża, Poland vs $30.7 \% ; p=0.0078)$. Hospitalisations in TTC patients were less frequently complicated by pneumonia $(20.0 \%$ vs $35.6 \% ; p=0.0148)$ and urinary infection $(4.2 \%$ vs $21.8 \%$; $p=0.0003)$. Cardiac rupture occurred in 3 patients with TTC and in 1 with anterior STEMI. In-hospital mortality was significantly lower in the group with TTC. Also, mortality at 30 days, 3 months, 1 year and 2.5 years was significantly lower in patients with TTC than in patients with MI ( $p=0.035 ; p=0.0226 ; p=0.0075 ; p=0.009)$.

Conclusions Previously considered to be a benign syndrome, TTC should be reconsidered as a clinical condition at risk for serious complications such as cardiac arrest, cardiogenic shock, pulmonary oedema and cardiac rupture leading to death and causing substantial early hazard. The prognosis in TTC is significantly better than in patients with anterior STEMI.

Keywords Takotsubo cardiomyopathy $\cdot$ Anterior myocardial infarction

\section{Introduction}

Takotsubo cardiomyopathy (TTC), also called 'apical ballooning syndrome' is a clinical condition, in which there are transient contractility disturbances of the apex of the left ventricle and ischaemic changes on the electrocardiogram (ECG) without significant luminal narrowing of the coronary arteries [1-3].

TTC was described for the first time by Sato et al. [1] in Japan in 1990. The name of the syndrome comes from a vessel with a narrow upper part and broad bottom used for catching octopus. This vessel resembles the shape of the left ventricle, as seen on ventriculography in patients with 'apical ballooning syndrome' [2]. 
TTC usually appears in women aged $60-80$ years with several cardiovascular risk factors. The syndrome is usually provoked by either mental or physical stress, which is why it is also called 'stress cardiomyopathy'.

The clinical course of TTC is similar to myocardial infarction and accounts for $1 \%$ of all cases of acute coronary syndromes (ACS). The main symptom is usually chest pain. In laboratory tests an increased concentration of cardiac necrotic markers is observed. On ECG ischaemic changes are recorded [2-6]. TTC usually has a benign clinical course but some cases can be complicated by cardiogenic shock, heart failure, dangerous ventricular arrhythmias or even cardiac rupture and death [7-11].

The aim of the study was to assess the clinical course, comorbidities, complications, early and late mortality in a population with TTC as compared with patients with anterior myocardial infarction.

\section{Material and methods}

In the years 2008-2012, we enrolled 101 patients from the northern-eastern part of Poland hospitalised due to TTC in the Department of Cardiology of the University Hospital in Bialystok and four other cardiology invasive centres (Department of Invasive Cardiology, Medical University of Bialystok; Department of Cardiology, ProCardia in Augustow; Department of Cardiology, Provincial Hospital in Bialystok; Department of Cardiology, Provincial Hospital in Lomza).

Demographic data, cardiovascular risk factors, clinical course during hospitalisation, results of laboratory tests, echocardiography and coronary angiography results were recorded. Only patients with TTC according to the Mayo Clinic criteria were included in the analysis (all four criteria must had been fulfilled):

- Transient hypokinesis, akinesis or dyskinesis of the left ventricular mid segments with or without apical involvement. The regional wall motion abnormalities typically extend beyond a single epicardial coronary distribution. A stressful trigger is often but not always present.

- Absence of obstructive coronary disease or angiographic evidence of acute plaque rupture.

- New electrocardiographic abnormalities (either ST-segment elevation and/or T-wave inversion) or modest elevation in cardiac troponin.

- Absence of pheochromocytoma or myocarditis. [12]

Five patients were excluded from the analysis, because they were diagnosed with TTC despite significant narrowing in the coronary vessels and one patient due to a muscle bridge in the left anterior descending coronary artery (LAD) with $95 \%$ narrowing during systole.
Obstructive coronary artery disease (CAD) was defined as a narrowing of $\geq 50 \%$ of the diameter of the vessel. Nonobstructive CAD was defined as any narrowing $<50 \%$.

The control group consisted with female patients diagnosed with acute anterior myocardial infarction with STsegment elevation (anterior STEMI) hospitalised in the Department of Invasive Cardiology, Medical University of Bialystok in the years 2008-2012 $(n=101)$. The control group matched the study population regarding age and sex.

Anterior STEMI was diagnosed according to the following criteria:

- Clinical symptoms such as chest pain,

- Elevation of cardiac troponin concentration $(>0.3 \mathrm{ng} / \mathrm{ml})$,

- ST elevation at the $\mathrm{J}$ point in two contiguous anterior leads ( $\geq 0.1 \mathrm{mV}$ in $\mathrm{V} 1$ and $\mathrm{V} 4-\mathrm{V} 6$; $\geq 0.15 \mathrm{mV}$ in V2-V3).

The primary endpoint was all-cause mortality in a 2-year follow-up. All data were obtained from the Polish population registry in Bialystok (Podlasie Province Office) or by telephone contact with the patients. The study protocol conformed with the ethical guidelines of the 1975 Declaration of Helsinki, and was approved by the local ethics committee (no R-I-002/26/2013).

\section{Statistical analysis}

Distribution of each variable was tested with the Kolmogorov-Smirnov test. Afterwards the Student's t test or the Mann-Whitney U test were used for statistical analysis where applicable. Additional analysis of correlations between non-categorical variables was performed using Pearson or Spearman tests, where applicable. Survival rates were displayed with Kaplan-Meier curves. Multivariate logistic regression was used to test associations between variables and outcomes. Data are expressed as means and standard deviations. Relative frequencies are used to present categorical variables. These variables were assessed by the $\chi^{2}$ test. A $p$ value of less than 0.05 was considered to be statistically significant. The statistic software NCSS 2010 was used.

\section{Results}

Demographic characteristics of the population are shown in Table. $1 ; 89 \%$ of the study group were women. Patients with TTC had diabetes ( $12.6 \%$ vs $29.7 \% ; p=0.002)$ and hyperlipidaemia (36.8\% vs $64.4 \% ; p=0.0001)$ significantly less frequently, and a better kidney function assessed by estimated glomerular filtration rate (eGFR) as compared 
Table 1 Clinical characteristics, concomitant diseases, clinical course and complications

\begin{tabular}{|c|c|c|c|}
\hline & $\begin{array}{l}\text { TTC } \\
n=95 \text { (SD) }\end{array}$ & $\begin{array}{l}\text { Anterior STEMI } \\
n=101 \text { (SD) }\end{array}$ & $p$ \\
\hline \multicolumn{4}{|l|}{ Clinical characteristics } \\
\hline - Age (years) & $67.6(14.2)$ & $72.1(13.1)$ & 0.023 \\
\hline - Female sex & $89.5 \%$ & $100 \%$ & - \\
\hline - Body mass index, $\mathrm{kg} / \mathrm{m}^{2}$ & $25.8(4.9)$ & $26.5(6.0)$ & 0.423 \\
\hline - Previous myocardial infarction & $4.2 \%$ & $8.0 \%$ & 0.271 \\
\hline - History of hypertension & $63.2 \%$ & $68.3 \%$ & 0.447 \\
\hline - Diabetes & $12.6 \%$ & $29.7 \%$ & 0.002 \\
\hline - Hyperlipidaemia & $36.8 \%$ & $64.4 \%$ & 0.0001 \\
\hline - Smoking & $21 \%$ & $26.3 \%$ & 0.383 \\
\hline - Family history of CAD & $16.8 \%$ & $18.2 \%$ & 0.806 \\
\hline \multicolumn{4}{|l|}{ Concomitant diseases } \\
\hline - Previous stroke & $3.2 \%$ & $8.9 \%$ & 0.097 \\
\hline - History of malignancy & $4.2 \%$ & $3.0 \%$ & 0.651 \\
\hline - COPD & $11.6 \%$ & $1.0 \%$ & 0.002 \\
\hline - Anxiety/depression & $8.4 \%$ & $6 \%$ & 0.515 \\
\hline - Thyroid disorders & $23.4 \%$ & $11.0 \%$ & 0.021 \\
\hline Hypothyroidism & $8.5 \%$ & $7.0 \%$ & 0.694 \\
\hline Hyperthyroidism & $10.6 \%$ & $3.0 \%$ & 0.0335 \\
\hline Goitre in euthyreosis & $4.3 \%$ & $1.0 \%$ & 0.147 \\
\hline \multicolumn{4}{|l|}{ Symptoms on admission } \\
\hline - Retrosternal chest pain & $83.2 \%$ & $96.7 \%$ & 0.0015 \\
\hline - Dyspnoea & $10.5 \%$ & $9.9 \%$ & 0.889 \\
\hline - Systolic BP (mmHg) & $128.22(25.99)$ & $133.78(26.65)$ & 0.141 \\
\hline - Diastolic BP (mmHg) & $77.13(15.29)$ & $82.47(15.24)$ & 0.015 \\
\hline - Heart rate on admission & $83.75(18.55)$ & $88.10(17.76)$ & 0.095 \\
\hline - Hearty rate on discharge & $69.61(12.34)$ & $80.92(18.00)$ & $<0.0001$ \\
\hline - Sudden cardiac arrest & $5.3 \%$ & $19.8 \%$ & 0.0023 \\
\hline - Pulmonary oedema & $6.3 \%$ & $14.85 \%$ & 0.0535 \\
\hline - Cardiogenic shock & $5.3 \%$ & $14.85 \%$ & 0.0267 \\
\hline - Cardiac arrest, pulmonary oedema, cardiogenic shock & $14.7 \%$ & $30.7 \%$ & 0.0078 \\
\hline \multicolumn{4}{|l|}{ Complications } \\
\hline - Pneumonia & $20.0 \%$ & $35.6 \%$ & 0.0148 \\
\hline - Respiratory failure & $7.4 \%$ & $10.9 \%$ & 0.393 \\
\hline - Urinary tract infection & $4.2 \%$ & $21.8 \%$ & 0.0003 \\
\hline - Rhythm disturbances & $10.5 \%$ & $12.9 \%$ & 0.381 \\
\hline Paroxysmal atrial fibrillation & $6.3 \%$ & $9.9 \%$ & 0.357 \\
\hline Ventricular tachycardia & $2.1 \%$ & $3.0 \%$ & 0.690 \\
\hline - AKI/CIAKI & $0.0 \%$ & $7.9 \%$ & 0.0198 \\
\hline AKI & $0.0 \%$ & $3.96 \%$ & 0.0508 \\
\hline CIAKI & $0.0 \%$ & $3.96 \%$ & 0.0508 \\
\hline - Cardiac rupture & $3.16 \%$ & $1.0 \%$ & 0.283 \\
\hline - Stroke & $0.0 \%$ & $4.95 \%$ & 0.0280 \\
\hline - Hospital psychosis & $4.2 \%$ & $6.9 \%$ & 0.411 \\
\hline In-hospital mortality & $3.16 \%$ & $9.90 \%$ & 0.0581 \\
\hline Discharge home & $73.7 \%$ & $51.5 \%$ & 0.0014 \\
\hline Transfer to either hospital, department & $23.2 \%$ & $40.0 \%$ & 0.0116 \\
\hline District hospital & $17.9 \%$ & $33.7 \%$ & 0.0118 \\
\hline Intensive care unit & $5.3 \%$ & $6.3 \%$ & 0.765 \\
\hline Mean hospitalisation time & $5.33(4.41)$ & $5.41(2.80)$ & 0.879 \\
\hline
\end{tabular}

$T T C$ takotsubo cardiomyopathy, $C A D$ coronary artery disease, $C O P D$ chronic obstructive pulmonary disease, $B P$ blood pressure, $A K I$ acute kidney insufficiency, CIAKI contrast-induced acute kidney insufficiency 
with patients with anterior STEMI (74.52 vs 64.30; $p=$ 0.004) (Table 1, respectively).

In the group with TTC there were more patients with chronic obstructive pulmonary disease (COPD) $(11.6 \%$ vs $1.0 \% ; p=0.002$ ) and thyroid disturbances, especially hyperthyroidism, as compared with the population with anterior STEMI ( $23.4 \%$ vs $11.0 \%$; $p=0.021$ ). Data on comorbidities are shown in Table 1.

The main symptom in patients with TTC was retrosternal pain, but this was less frequent than in the population with anterior STEMI ( $83.2 \%$ vs $96.7 \%$. $p=0.0015)$. In patients with TTC, sudden cardiac arrest, pulmonary oedema and cardiogenic shock were observed less frequently than in the control group (14.7\% vs 30.7\%; $p=0.0078$ ) (Table 1 ).

\section{Ischaemic changes on ECG}

In $55 \%$ of patients with TTC, ST-segment elevation was present on admission to hospital, while in almost every third patient T-wave inversion was recorded. During hospitalisation, deep negative $\mathrm{T}$ waves were observed in $92 \%$ of the population with TTC. Also, a significantly prolonged QTc interval was recorded on the 5th day of hospitalisation in patients with TTC as compared with patients with anterior STEMI.

In the population with TTC there were fewer episodes of atrial fibrillation ( $5.3 \%$ vs $13.9 \%$; $p=0.042)$. Other data on cardiac arrhythmias and conductibility disturbances are shown in Table 2.

\section{Coronary angiography}

In $44 \%$ of the patients with TTC no atherosclerotic changes were observed; in the remaining $56 \%$ of the population changes were insignificant (Table 2).

\section{Echocardiography and ventriculography}

In 95 patients typical contractility disturbances with apical involvement on echocardiography and ventriculography were recorded. We observed transient akinesis of the left ventricular mid segments without apical involvement in one patient. Mean left ventricular ejection fraction (LVEF) was $39.8 \%$ and was significantly higher than in patients with anterior STEMI $(35.09 \%, p=0.001)$. On control echocardiography, performed in $30 \%$ of the patients with TTC, improvement of LVEF was recorded (mean LVEF $48.8 \%$ ). Other echocardiographic and angiographic data are shown in Table 2.

\section{Cardiac necrotic markers and other laboratory parameters}

Of the patients with TTC, $87.4 \%$ had a significantly raised concentration of cardiac necrotic markers (troponins) but the increase in concentration of cardiac markers was lower than in the population with anterior STEMI (5.32 vs 27.27; $p<0.0001$ ). The population with TTC had also a lower white cell count $(9.73$ vs $12.17 ; p<0.0001)$ and lower concentrations of inflammatory parameters such as fibrinogen (409.53 vs 462.66; $p=0.033$ ). Patients with TTC had lower glucose concentrations on admission (126.85 vs 180.83 ; $p<0.0001)$ and lower concentrations of total cholesterol (182.07 vs 209.51; $p=0.0001)$ and low-density cholesterol ( 110.50 vs $140.40 ; p<0.0001)$. Patients with STEMI had a significantly higher concentration of creatinine and lower eGFR assessed by the MDRD formula (74.52 vs 64.30; $p=$ 0.004) (Table 2).

\section{Clinical course and complications}

Hospitalisation in TTC patients was less frequently complicated by pneumonia $(20.0 \%$ vs $35.6 \% ; p=0.0148)$ and urinary infection $(4.2 \%$ vs $21.8 \% ; p=0.0003)$. No cases of renal failure and strokes were recorded. Cardiac rupture occurred in three patients with TTC and in one with anterior STEMI.

The majority of the patients with TTC were discharged home. The patients from the control group were more frequently transferred to other wards and district hospitals (17.9\% vs $33.7 \% ; p=0.0118)$. Other data on clinical course and complications are shown in Table 1.

Data on pharmacological treatment are shown in Table 3.

\section{Early and late prognosis}

In-hospital mortality was significantly lower in the group with TTC. Of three patients who died during hospitalisation, two had a cardiac rupture and one brain injury after a long resuscitation. Mortality at 30 days, 3 months, 1 year and 2.5 years was significantly lower in patients with TTC than in patients with anterior STEMI $(p=0.035 ; p=0.0226$; $p=0.0075 ; p=0.009$ ) (Table 1, Fig. 1.).

\section{Discussion}

Over 20 years have passed by since TTC was described by Sato et al. but 'apical ballooning syndrome' remains a poorly defined disease entity when it comes to aetiology and management. 
Table 2 Electrocardiogram, echocardiography, angiography and laboratory parameters

\begin{tabular}{|c|c|c|c|}
\hline & $\begin{array}{l}\text { TTC } \\
n=95 \text { (SD) }\end{array}$ & $\begin{array}{l}\text { Anterior STEMI } \\
n=101 \text { (SD) }\end{array}$ & $p$ \\
\hline \multicolumn{4}{|l|}{ Electrocardiogram } \\
\hline \multicolumn{4}{|l|}{ - Rhythm on admission } \\
\hline Sinus rhythm & $91.5 \%$ & $86.1 \%$ & 0.232 \\
\hline Atrial fibrillation & $5.3 \%$ & $13.9 \%$ & 0.042 \\
\hline Pacemaker rhythm & $3.2 \%$ & $0.0 \%$ & 0.084 \\
\hline - Conduction disorders & $17.9 \%$ & $24.8 \%$ & 0.240 \\
\hline LBBB/RBBB & $6.3 \%$ & $9.92 \%$ & 0.355 \\
\hline LBBB & $4.2 \%$ & $2.0 \%$ & 0.372 \\
\hline RBBB & $2.1 \%$ & $7.92 \%$ & 0.064 \\
\hline Left anterior hemiblock & $8.4 \%$ & $10.9 \%$ & 0.554 \\
\hline First-degree atrioventricular block & $3.2 \%$ & $4.95 \%$ & 0.537 \\
\hline - ST elevation & $54.7 \%$ & $100 \%$ & $<0.0001$ \\
\hline - ST depression & $4.2 \%$ & $2.0 \%$ & 0.372 \\
\hline - T-wave inversion & $23.2 \%$ & $2.0 \%$ & $<0.0001$ \\
\hline - Deep T-wave inversion (after a few days) & $92.2 \%$ & $66.3 \%$ & $<0.0001$ \\
\hline - QT on admission (ms) & $406.7(50.08)$ & $395.04(45.16)$ & 0.156 \\
\hline - QTc on admission (ms) & $468.86(38.66)$ & $465.59(28.07)$ & 0.561 \\
\hline - QT after a few days & $449.72(57.73)$ & $414.45(48.48)$ & 0.0002 \\
\hline - QTc after a few days & $476.73(84.49)$ & $469.87(30.85)$ & 0.494 \\
\hline \multicolumn{4}{|l|}{ Echocardiography/ventriculography } \\
\hline \multicolumn{4}{|l|}{ - Left ventricular ejection fraction $(\%)$} \\
\hline EF on admission $(\%)$ & $39.9(9.9)$ & $35.1(9.8)$ & 0.001 \\
\hline EF after a few days - mean $4(\%)$ & $48.8(9.9)$ & - & - \\
\hline - Left ventricular diameter on admission (mm) & $47.6(4.8)$ & $45.8(5.2)$ & 0.014 \\
\hline - Apical variant of TTC & $99 \%$ & - & - \\
\hline - Midventricular variant of TTC & $1.05 \%$ & - & - \\
\hline \multicolumn{4}{|l|}{ Coronarography } \\
\hline No atherosclerotic changes in coronary arteries & $44.2 \%$ & - & - \\
\hline Insignificant stenosis & $55.8 \%$ & $3.0 \% \mathrm{a}$ & - \\
\hline Significant stenosis & - & $95 \%^{\mathrm{a}}$ & - \\
\hline \multicolumn{4}{|l|}{ Laboratory parameters } \\
\hline - Haemoglobin (mg/dl) & $13.35(1.63)$ & $13.10(1.35)$ & 0.236 \\
\hline - Erythrocytes $(\mathrm{mln} / \mu \mathrm{l})$ & $4.49(0.65)$ & $4.40(3.68)$ & 0.263 \\
\hline - Haematocrit (\%) & $39.54(6.13)$ & $39.36(3.68)$ & 0.808 \\
\hline - Leukocytes (thousands/ $\mu 1$ ) & $9.73(3.96)$ & $12.17(4.18)$ & $<0.0001$ \\
\hline - Platelets (thousands/ $\mu \mathrm{l}$ ) & $245.59(93.32)$ & $243.73(76.77)$ & 0.055 \\
\hline - Creatinine (mg/dl) & $0.90(0.37)$ & $1.02(0.65)$ & 0.121 \\
\hline - eGFR MDRD & $74.52(27.21)$ & $64.30(22.28)$ & 0.004 \\
\hline - ASAT (IU/l) & $48.79(35.13)$ & $80.01(107.71)$ & 0.027 \\
\hline - ALAT (IU/l) & $31.48(34.26)$ & $39.94(55.49)$ & 0.277 \\
\hline - Creatine kinase (IU/l) & $435.62(940.52)$ & $1966.37(2378.18)$ & $<0.0001$ \\
\hline - CK-MB (IU/l) & $50.15(72.39)$ & $280.76(318.5)$ & $<0.0001$ \\
\hline - Troponin I, mean concentration (ng/ml) & $5.32(11.66)$ & $27.27(20.98)$ & $<0.0001$ \\
\hline - Glycaemia on admission (mg/dl) & $126.85(47.35)$ & $180.83(87.08)$ & $<0.0001$ \\
\hline - Total cholesterol (mg/dl) & $182.07(41.27)$ & $209.51(50.14)$ & 0.0001 \\
\hline - Low-density lipoprotein (mg/dl) & $110.50(38.12)$ & $140.40(46.83)$ & $<0.0001$ \\
\hline
\end{tabular}


Table 2 Electrocardiogram, echocardiography, angiography and laboratory parameters (Continued)

\begin{tabular}{llll}
\hline & TTC & Anterior STEMI & $p$ \\
$n=101(\mathrm{SD})$ & & \\
\hline - High-density lipoprotein $(\mathrm{mg} / \mathrm{dl})$ & $52.35(17.48)$ & $50.21(17.94)$ & 0.425 \\
- Triglycerides (mg/dl) & $98.71(52.12)$ & $104.65(68.29)$ & 0.520 \\
- Fibrinogen (mg/dl) & $409.53(160.08)$ & $462.66(147.90)$ & $\mathbf{0 . 0 3 3}$ \\
\hline
\end{tabular}

$\angle B B B$ left bundle branch block, $R B B B$ right bundle branch block, $T T C$ takotsubo cardiomyopathy

an two patients with anterior STEMI, coronary angiography was not carried out and they were treated conservatively due to a long delay between the onset of chest pain and hospital admission

Table 3. Pharmacological treatment and intra-aortic balloon pump (IABP)

\begin{tabular}{|c|c|c|c|}
\hline & $\begin{array}{l}\text { TTC (\%) } \\
n=95(\mathrm{SD})\end{array}$ & $\begin{array}{l}\text { Anterior STEMI (\%) } \\
n=101 \text { (SD) }\end{array}$ & $p$ \\
\hline GP IIb/IIIa inhibitors & - & 31,7 & - \\
\hline - Abciximab & - & 12.9 & - \\
\hline - Eptifibatide & - & 18.8 & - \\
\hline Heparin & 91.6 & 98.0 & 0.0419 \\
\hline - Unfractionated heparin & 36.8 & 57.4 & 0.0038 \\
\hline - Enoxaparin & 52.6 & 40.6 & 0.092 \\
\hline - Fondaparinux & 2.1 & 0.0 & 0.146 \\
\hline Nitroglycerin & 14.7 & 31.7 & 0.0051 \\
\hline Clopidogrel & 82.1 & 99 & $<0.0001$ \\
\hline Aspirin & 97.9 & 98.0 & 0.951 \\
\hline Statins & 89.5 & 86.1 & 0.477 \\
\hline Beta blockers & 87.4 & 89.1 & 0.705 \\
\hline ACEI/ARB & 89.5 & 82.2 & 0.144 \\
\hline ACEI & 82.1 & 79.2 & 0.608 \\
\hline ARB & 7.4 & 3.0 & 0.163 \\
\hline Calcium blockers & 8.4 & 5.9 & 0.501 \\
\hline Diuretics & 49.5 & 70.3 & 0.0029 \\
\hline Proton pump inhibitors & 74.7 & 90.1 & 0.0045 \\
\hline Pressor amines & 13.7 & 22.0 & 0.130 \\
\hline Intra-aortic balloon pump & 2.11 & 7.14 & 0.097 \\
\hline
\end{tabular}

$A C E I$ angiotensin-converting enzyme inhibitor, $A R B$ angiotensin receptor blocker, $I A B P$ intra-aortic balloon pump

In recent years, there were about 2,000 patients per year with MI in the northern-eastern part of Poland (Podlasie Province, data from general cardiology consultant Professor G. Opolski). In the years 2008-2012, 95 patients were diagnosed with TTC in all catheterisation laboratories in Podlasie Province, which accounts for $1 \%$ of all acute coronary syndromes. Stress cardiomyopathy appears mainly in middle-aged women ( $89 \%$ of our study group). In the similar group with TTC investigated by Tsuchihashi et al. [13] $86 \%$ were women; the mean age was 67 . In other published data, women account for $80-100 \%$ of the population with a mean age of $61-76$ years $[5,14]$. It is worth noting that TTC may also be diagnosed in younger women. In our group the youngest female was 15 years old, the oldest was 100 years.

In our population with TTC, similarly to data from the literature, we observed less cardiovascular risk factors than in patients with anterior STEMI but more cases of COPD $(11.6 \%)$ and thyroid disturbances (23.4\%), mainly hyperthyroidism [5].

Disturbances in thyroid function in patients with TTC had already been noticed by other investigators. Sarullo et al. [15] analysed TTC in patients with hyperthyroidism while Cacciotti et al. [16] found hypothyroidism in $29.3 \%$ of their patients with stress cardiomyopathy. The association between hyperthyroidism and hypothyroidism and TTC remains unclear, but many investigators suggest focusing on thyroid function.

In a few papers, COPD was included in the clinical characteristics of the patients with TTC, but only rare single cases were described in which stress cardiomyopathy was linked with COPD as provoking factor. Among other provoking factors, asthma, mental and physical strain were mentioned [13, 17]. 

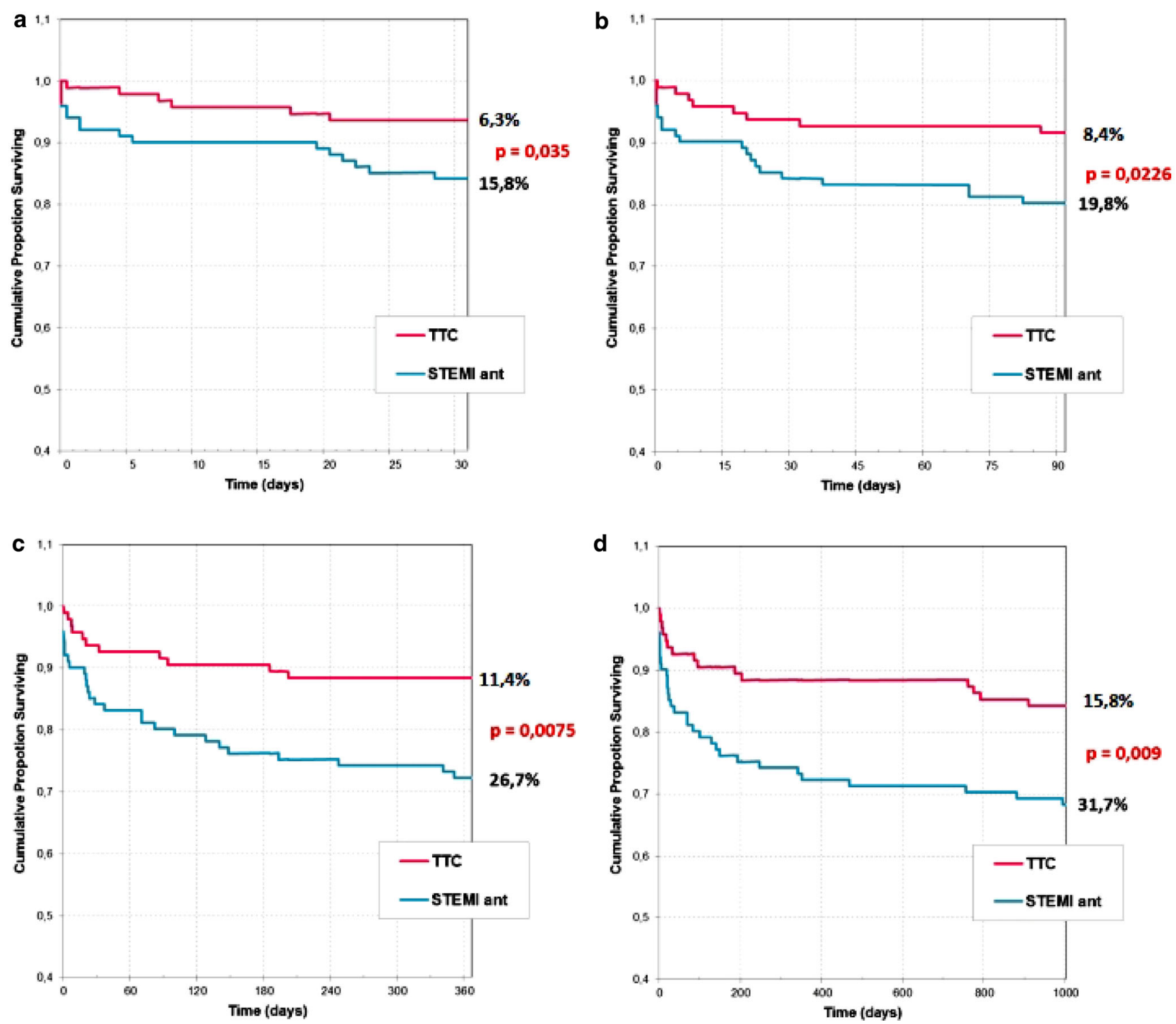

Fig. 1a-d Kaplan-Meier curves showing survival in patients diagnosed with Takotsubo cardiomyopathy and anterior ST-segment elevation myocardial infarction at 30-day, 3-month, 1-year and 2.5-year follow-up

The main symptom in TTC was retrosternal chest pain exactly the same as in STEMI. We observed chest pain in $83 \%$ of our patients. In other studies chest pain typical for MI was observed in 54-100\% of the patients with TTC [5].

In our group with TTC we observed serious complications, such as cardiogenic shock, pulmonary oedema and cardiac arrest, significantly less frequently than in patients with anterior STEMI. These adverse cardiovascular events occurred in $14.7 \%$ of the patients with TTC. In other publications cardiogenic shock and pulmonary oedema were observed more often. According to Tsuchihashi et al. [13] pulmonary oedema was observed in $22 \%$ of patients with TTC, and $8 \%$ needed intra-aortic counterpulsation. Surprising data were published by Song et al. [17]. They observed cardiogenic shock in $35 \%$ and pulmonary oedema in $42 \%$ of their patients with TTC. On the other hand Parodi et al. [18] reported cardiogenic shock in $5 \%$ of their population with TTC.

In our study 3 patients $(3.16 \%)$ with TTC had cardiac rupture, while in the anterior STEMI group in which there is a high risk of cardiac rupture - only one. In their systematic analysis, Kumar et al. [9] described 12 cases of cardiac rupture in patients with TTC. Ten patients out of 12 died. In the majority of them perforation of the left ventricular wall was confirmed on autopsy. In our study 2 patients died. One female with cardiac rupture in the apex of the left ventricle diagnosed on ventriculography survived thanks to urgent cardiac surgery.

In-hospital and late mortality were significantly lower in the group with TTC than in patients with MI. During 
hospitalisation, $3(3.16 \%)$ patients with TTC died due to cardiac complications. Exactly the same $3 \%$ in-hospital mortality due to cardiovascular reasons was reported by Nunez-Gil et al. [19] and 2\% cardiovascular mortality by Parodi et al. [18] In some observational studies there were no deaths in patients with TTC during hospitalisation but according to other authors mortality is much higher and even reached $8 \%$ [20]. After 2.5 years, $15.8 \%$ of our study patients had died. The reasons of death were not connected with cardiovascular reasons but mainly with cancer. Song et al. [17] observed $9 \%$ mortality after 5-year follow-up. The reasons of death were non-cardiac.

TTC is one of the least known cardiac diseases. Although clinical presentation is similar to MI, the prognosis is much better. Nevertheless it is worth noting that the course of TTC can be complicated by serious events such as cardiac rupture, pulmonary oedema, cardiac arrest which causes substantial early hazard.

\section{Study limitations}

Takotsubo cardiomyopathy was diagnosed according to Mayo Clinic criteria. Of the patients from takotsubo group, $56 \%$ had non-obstructive CAD. We could not exclude spasm and spontaneous thrombolysis in patients with nonobstructive CAD.

\section{Conclusions}

Previously considered to be a benign syndrome, TTC should be reconsidered as a clinical condition at risk of serious complications such as cardiac arrest, cardiogenic shock, pulmonary oedema and cardiac rupture leading to death. The TTC population was diagnosed with a significantly higher rate of COPD and thyroid disorders than patients with STEMI. Early and late prognosis in patients with TTC is better than in patients with anterior STEMI.

\section{Funding None}

Conflict of interest M. Zalewska-Adamiec, H. Bachorzewska-Gajewska, A. Tomaszuk-Kazberuk, K. Nowak, P. Drozdowski, J. Bychowski, R. Krynicki, W.J. Musial and S. Dobrzycki state that there are no conflicts of interest.

Open Access This article is distributed under the terms of the Creative Commons Attribution 4.0 International License (http:// creativecommons.org/licenses/by/4.0/), which permits unrestricted use, distribution, and reproduction in any medium, provided you give appropriate credit to the original author(s) and the source, provide a link to the Creative Commons license, and indicate if changes were made.

\section{References}

1. Sato H, Tateishi H, Uchida T, et al. Tako-tsubo-like left ventricular dysfunction due to multivessel coronary spasm. In: Kodama K, Haze K, Hori M, editors. Clinical aspect of myocardial injury: from ischemia to heart failure. Tokyo: Kagakuhyoronsha Publishing; 1990. pp. 56-64.

2. Nef HM, Mollmann H, Elsasser A. Tako-Tsubo cardiomyopathy (apical ballooning). Heart. 2007;93:1309-15.

3. Sharkey SW, Lesser JR, Zenovich AG, et al. Acute and reversible cardiomyopathy provoked by stress in women from the United States. Circulation. 2005;111:472-9.

4. Prasad A. Apical ballooning syndrome: an important differentia diagnosis of acute myocardial infarction. Circulation. 2007;115:e56-e59.

5. Pelliccia F, Parodi G, Greco C, et al. Comorbidities frequency in Tako-Tsubo syndrome: an international collaborative systematic review including 1109 patients. Am J Med. 2015;128:654:e11-9.

6. Gianni M, Dentali F, Grandi AM, et al. Apical ballooning syndrome or Tako-Tsubo cardiomyopathy: a systematic review. Eur Heart J. 2006;27:1523-9.

7. Kawai S, Suzuki H, Yamaguchi H, et al. Ampulla cardiomyopathy ('Tako-Tsubo' cardiomyopathy) - reversible left ventricular dysfunction: mith ST segment elevation. Jpn Circ J. 2000;64:156-9.

8. Kurisu S, Sato H, Kawagoe T, et al. Tako-Tsubo-like left ventricular dysfunction with ST-segment elevation: A novel cardiac syndrome mimicking acute myocardial infarction. Am Heart J. 2002;143:448-55.

9. Kumar S, Kaushik S, Nautiyal A, et al. Cardiac rupture in Tako-Tsubo cardiomyopathy: a systematic review. Clin Cardiol. 2011;34:672-6.

10. Ter BE, Odekerken DA, Somsen GA. Tako-Tsubo cardiomyopathy complicated by cardiac tamponade. Neth Heart J. 2014;22:246-8. doi:10.1007/s12471-013-0458-z.

11. Postema PG, Wiersma JJ, Bilt IA van der, et al. Tako-Tsubo cardiomyopathy shortly following pacemaker implantation-case report and review of the literature. Neth Heart J. 2014;22:456-9. doi:10.1007/s12471-012-0320-8.

12. Bybee K, Kara T, Prasad A, et al. Systematic review: transient left ventricular apical ballooning: a syndrome that mimics acute myocardial infarction. Ann Intern Med. 2004;141:858:65.

13. Tsuchihashi K, Ueshima K, Uchida T, et al. Transient left ventricular apical ballooning without coronary artery stenosis: a novel heart syndrome mimicking acute myocardial infarction: Angina Pectorismyocardial infarction investigations in Japan. J Am Coll Cardiol. 2001;38:11-8.

14. Akashi YJ, Goldstein DS, Barbaro G, et al. Tako-Tsubo cardiomyopathy: a new form of acute, reversible heart failure. Circulation. 2008; 118:2754-62.

15. Sarullo FM, Di Franco A, Di Monaco A, et al. Tako-Tsubo cardiomyopathy and thyroid dysfunction. Int $\mathrm{J}$ Endocrinol Metab. 2011;9:369-72. doi:10.5812/Kowsar.1726913X.3386.

16. Cacciotti L, Passaseo I, Marazzi G, et al. Observational study on Tako-Tsubo - like cardiomyopathy: clinical features, diagnosis, prognosis and follow-up. BMJ Open. 2012;2:e001165 doi:10.1136/bmjopen-2012-001165.

17. Song BG, Yang HS, Hwang HK, et al. The impact of stressor patterns on clinical features in patients with Tako-Tsubo cardiomyopathy: experiences of two tertiary cardiovascular centers. Clin Cardiol. 2012;35,11:E6-E13.

18. Parodi G, Bellandi B, Del Pace S, et al. Natural history of TakoTsubo cardiomyopathy. Chest. 2011;139:887-92. 
19. Nunez-Gil IJ, Molina M, Bernardo EE, et al. Tako-Tsubo syndrome and heart failure: long-term follow-up. Rev Esp Cardiol. 2012;65:996-1002.
20. Kurowski V, Kaiser A, Hof K von, et al. Apical and midventricular transient left ventricular dysfunction syndrome (Tako-Tsubo cardiomyopathy): frequency, mechanisms, and prognosis. Chest. 2007;132:809-16. 